\title{
Behavioral and Cognitive Management of Panic Disorder and Agoraphobia in Adolescents: A Case Report
}

\author{
Amraouza K*, Rabitateddine M, EL Barmaki N, Adali I, Manoudi F, Asri F
}

Research Team for Mental Health, University Department of Psychiatry, Mohammed VI University Hospital Center, Marrakech, Morocco

DOI: $10.36347 /$ simcr.2020.v08i03.005

| Received: 24.02.2020 | Accepted: 02.03.2020 | Published: 07.03.2020

*Corresponding author: Amraouza $\mathrm{K}$

Abstract

Children and adolescents are increasingly at risk of developing mental health issues, which negatively impact their development in their societies'. Anxiety disorders are common in this population and their management is based on psychotherapy. We're reporting the case of a teenage girl with panic disorder associated with agoraphobia. We have proposed Cognitive behavioural therapy (CBT) as a care method. Several meta-analysis studies have shown its effectiveness in anxiety disorders. This far, studies are mainly conducted among adult population and there is few data about children and adolescents. In Morocco, child and adolescent psychiatry is a new specialty, and CBT is still very little used. In our case, panic attacks and agoraphobia were controlled at the end of therapy, and no relapse was reported after 2 years. These results make us focus on CBT as a major care method in treating young population's anxiety disorders.

Keywords: Panic disorder, agoraphobia, Cognitive behavioural therapy, adolescents.

Copyright @ 2020: This is an open-access article distributed under the terms of the Creative Commons Attribution license which permits unrestricted use, distribution, and reproduction in any medium for non-commercial use (NonCommercial, or CC-BY-NC) provided the original author and source are credited.

\section{INTRODUCTION}

Fear is a primary emotion. It appears early in young age and contributes positively to children's psychological development. However, it can turn pathological when it becomes too intense or when it appears in inappropriate situations. It, therefore, leads to anxiety disorders which represent the most common psychiatric disorders in young people [1]. Panic disorder is one of the common anxiety disorders in adolescents. Its prevalence in the general population varies between 2 to $4 \%$ with a female predominance [2]. In the fifth edition of the Diagnostic and Statistical Manual of Mental Disorders (DSM-5), panic disorder was separated from agoraphobia [3, 4]. In our study, we report the case of a 14-year-old girl suffering from panic disorder and agoraphobia. The behavioral and cognitive management of the patient showed the effectiveness of this approach in teens.

\section{Clinical Case}

Miss F is a 14-year-old girl. She was sent in child and adolescent psychiatry consultation by her cardiologist. Being the only girl and the youngest, she has always been overprotected by family members. She suffered from separation anxiety during her childhood. At school, she was a model student: serious, intelligent and very calm. Symptoms started a year ago. Miss F had her first panic attack at school. Then, the number of panic attacks increased up to several times a day. Panic attacks were spontaneous and occurred in different situations. Therefore, Miss F began to avoid all situations where she could find herself alone. She was afraid that she would not be able to ask for help when needed. She was so afraid of panic attacks that she stopped doing several activities. She couldn't get out alone, did not play sport, and even refused to travel. She consulted emergency unit several times. She was afraid to have a heart attack. No organic cause including heart disease has been found. Her cardiologist referred her to a child and adolescent psychiatry consultation. We proposed Behavioral and cognitive management coupled with pharmacological treatment (selective serotonin reuptake inhibitor) for her.

Treatment length was up to 20 weekly individual sessions. First we worked on psychoeducation and we made a therapeutic contract in collaboration with both patient and her parents. Then, the Synchronic Functional Analysis focused on a situation "spontaneous panic attack at home". We used the "SECCA" grid [5].we indentified the emotion "fear" the physical symptoms of panic attack, the cognition or automatic thoughts "I will die" "my heart will stop", and the patient's behavior "stay frozen". Diachronic functional analysis reveals a genetic predisposition 
since the parents were suffering from a generalized anxiety disorder. The overprotection of family members doesn't help her. The therapeutic goals were to eliminate panic attacks and to overcome agoraphobia. We used measures to monitor the therapy progress. Beck's abbreviated depression inventory [6] showed an initial score of 23 which means moderate depression without suicidal thoughts. The scale of assessment of phobias, panic attacks and generalized anxiety "PPAG" [7] made it possible to measure the number of panic attacks. It could reach up to 10 per day. It also identified phobogenic situations. We use Beck's automatic thought record [8] to teach patient how to indentify, evaluate and modify her negative thoughts. We also classified the phobogenic situations using a hierarchical subjective evaluation. The anxiety degree was defined by the patient using a visual analogical scale from 0 to 10 so we could make a fear thermometer. Using this tool, we could conduct the exposures in a graduated way.

We used several techniques as well as a healthy lifestyle. Respiratory control using the "Valsalva" maneuver [5] allows the patient to reduce anxiety and to eliminate physical sensations that may arise from it. The patient was also trained to Jacobson's relaxation technique. Cognitive restructuring made it possible to change the automatic anxiety-provoking thoughts to alternative positive thoughts. The exposures were the most important stage of therapy. We explained to our patient the habituation principle. Exposure exercises were done in a graduated, prolonged and repeated way. They were first done in imagination. After training in sessions, the patient did exposures in vivo.

At the end of the therapy, the objectives were achieved. The panic attacks were controlled at the 10th session. Then the agoraphobia was managed by exposure exercises. Panic disorder was no longer a handicap for our patient. She regained self-confidence. Her school level had improved. She became autonomous. She was able to live new experiences and have new social relationships. Measures at the end revealed no depression. We followed our patient for 2 years after stopping pharmacological treatment. We did not notice any relapses during this period.

\section{DisCUSSION}

Nearly $25 \%$ of children and adolescents suffer from mental diseases [8]. Anxiety disorders are the most common diagnosis [1]. In young people, it has a negative impact on the development and life quality. This was clearly reported by our patient. Her academic performance was reduced as well as her social interactions. She became more and more isolated and she was afraid to have new experiences. According to the recommendations of the American Academy of Child and Adolescent Psychiatry (AACAP), Cognitive behavioural therapy (CBT) is the gold standard of treatment for panic disorder. It can be combined with pharmacotherapy, especially selective serotonin reuptake inhibitors, in severe anxiety disorders [9]. CBT is associated with a high rate of remission [10, 11]. Despite the success of this approach, the data concerning children and adolescents remain very limited and neglected compared to those concerning adults [12]. For our case, we chose to treat the patient using CBT + pharmacotherapy because of the severity of the disorder. We involved parents too. In children and adolescents, CBT follows the same pattern used for adults with adaptations according to the age. Also, the involvement of the parents is important to encourage their children especially for doing exposures [13]. The therapy was successful. A good therapeutic alliance was established between the therapist and the patient. She was very motivated to deal with her trouble. She was really engaged; enthusiast and she always respected the appointments. We congratulated her and encouraged her for doing homework in the right way. We always tried to increase her sense of self-efficacy in order to maintain her motivation and involvement with the therapy. This clinical case illustrates the effectiveness of CBT in the management of Panic disorder in adolescents. Indeed, we achieved complete remission with relapse prevention during the follow-up of our patient.

\section{CONCLUSION}

Our clinical case is an opportunity to show the high importance of CBT in the management of mental disorders in adolescents especially anxiety disorders. It allows us to encourage using this tharapy with young people and also publishing more data about it.

\section{REFERENCES}

1. Denis, Hélène. Traiter les troubles anxieux de L'Enfant ET l'adolescent du diagnostic à la prise en charge. DUNOD. 2017; 978-2-10-076961-2

2. Roy-Byrne PP, Craske MG, Stein MB. Panic disorder. Lancet. 2006; 368: 1023-32.

3. American Psychiatric Association. Diagnostic and statistical manual of mental disorders, 5th ed, Washington: American Psychiatric Association; 2013.

4. Katz C. Les troubles anxieux dans le DSM5: nouvelles règles sur le diagnostic et le traitement. CANMAT 2013; 3

5. Cottraux Jean. les psychothérapie comportementale et cognitive. Elsevier masson SAS. 2011. ISBN 978-2-294-70814-5

6. Collet L, Cottraux J. Inventaire abrégé de la dépression de Beck (13 items). Étude de la validité concurrente avec les échellesde Hamilton et de Widlcher. Encephale. 1986; 12:77-9.

7. Cottraux J, Bouvard M, Légeron P. Méthodes et échelles d'évaluation des comportements. Issy-lesMoulineaux: EAP; 1985. 
8. Merikangas KR, He JP, Burstein M, Swanson SA, AvenevoliS, Cui L. Lifetime prevalence of mental disorders inUS adolescents: results from the national comorbidity study-adolescent supplement (NCS-A). J Am Acad Child AdolescPsychiatry. 2010;49(10):980-9.

9. Connolly SD, Bernstein GA. Practice parameter for the assessment and treatment of children and adolescents with anxiety disorders. J Am Acad Child Adolesc Psychiatry. 2007; 46:267-83.

10. Cartwright-Hatton S, Roberts C, Chitsabesan P. Systematic review of the efficacité of cognitive behaviour therapies for childhood and adolescent anxiety disorders. Br J Clin Psychol. 2004; 43:42136.

11. Denis H. Les troubles anxieux de l'enfant et l'adolescent. Archives de pédiatrie; 2016.

12. Leclerc JB. La thérapie comportementale-cognitive ciblant les enfants et adolescents: enjeux et perspectives d'avenir. Journal de thérapie comportementale et cognitive; 2018.

13. Kendall PC, Kane M, Howard B. Cognitivebehavioral therapy for anxious children: treatment manual. Ardmore: Workbook Publishing; 1990. 